\title{
Editorial
}

\section{Muerte fetal intrauterina: Un evento devastador que nos convoca a mejorar las estrategias de monitoreo sobre eventos adversos en pos de desarrollar estrategias de prevención.}

La muerte fetal intrauterina es un evento devastador, aciago tanto para la familia como para el equipo médico. Es un cáliz muy amargo que nos descoloca y nos pone en una realidad no esperada. Para la familia, especialmente para la madre, la muerte de un hijo provoca un enorme sentimiento de pérdida y muchas veces de culpabilidad. Más importante aún, es un evento tan calamitoso que tiene un impacto psicológico enorme poniendo a prueba la relación médico paciente, y entre familiares, además de aquellas establecidas entre usuarios-clientes con proveedores y prestadores de salud. Para el médico constituye un gran desafío el explicar el evento adverso actual y prevenir uno futuro. Cuando los controles prenatales han sido adecuados y los exámenes de laboratorio están dentro de los parámetros normales, es difícil anticipar este final y menos comprender la génesis de dicho desenlace y por tanto, definir estrategias futuras que garanticen un resultado distinto en el embarazo siguiente.

La muerte fetal es la principal causa de la mortalidad perinatal en Chile y en el mundo. De hecho, la tasa de mortinatalidad es igual o superior a la tasa de mortalidad neonatal y las cifras superan los 4 a 5 millones de mortinatos ocurriendo en el tercer trimestre de la gestación. Un estudio de Lancet con datos obtenidos de 190 países del mundo estiman una tasa de mortinatalidad global de 23.9 y 25 por mil nacidos vivos en los países desarrollados y en los países en vías del desarrollo, respectivamente1. Sin embargo, tal similitud de indicador entre países con distinto nivel de desarrollo resulta engañosa y se explica en el gran déficit de registro que existe en los países del tercer mundo, una tarea pendiente para todos ellos y que impacta en la definición de políticas públicas vinculadas a la salud de la mujer.
La mayoría de las clasificaciones sobre causas de mortinatalidad se basan en la autopsia fetal que conlleva además una serie de estudios de laboratorio, incluyendo análisis genéticos y/o de biomarcadores, estudios anátomo patológicos (feto y placenta) y radiológicos (al feto). Para ciertas condiciones, el establecer la causalidad puede implicar realizar estudios a los padres y eventualmente hacer estudios de linaje. Muchas veces tales estudios encarecen el proceso sin mejorar la precisión diagnóstica. Dentro de los métodos para lograr una clasificación eficiente, y probablemente costo efectiva en países menos desarrollados, se encuentra el CORM (Condición Obstétrica Relevante de la Muerte fetal). El CORM considera el análisis conjunto por parte del obstetra y patólogo de los datos clínicos, de laboratorio e incorpora el estudio histopatológico de la placenta como una de las variables fundamentales2. A través de dicho método es posible identificar un porcentaje de causas evitables conocidas y otras no prevenibles minimizando los casos catalogados como de origen desconocido.

Lamentablemente, muchas veces no se realizan estudios para establecer causalidad porque el equipo médico a cargo no realiza consejería sobre la importancia de dicha acción hacia una madre y su familia que se enfrenta al dolor, inundados de sentimientos negativos y que a su vez, demanda explicaciones.

Como médicos aspiramos a una maternidad segura que propenda al mejor resultado perinatal para el binomio madre-hijo/a. Una parte importante para el proceso de prevención de eventos adversos obstétricos vinculados a mortalidad es lograr establecer con la mayor precisión posible la causa de dicha muerte. Esto es crítico para evitar su recurrencia. Con dicha finalidad, toda maternidad debiese contar con registros y protocolos de 
monitoreo de dichos casos. Este proceso facilita la revisión y evaluación de las acciones para permitir eventualmente mejorar los procesos a fin de minimizar los casos de muerte fetal evitable. El análisis de dichos casos no busca establecer culpabilidad o responsables sino identificar acciones, tanto por parte del equipo médico o familia, en las cuales hubo falla $y$ se requieren mejoras o cambios. Esto puede incluir protocolos clínicos de manejo y proceso de entrega de información y educación a la paciente y su familia. También es claro que todas estas acciones buscan aumentar la seguridad y minimizar la ocurrencia del evento adverso. Aunque no logre garantizar el éxito, contribuye a mitigar la culpa y dolor de todos frente a lo claramente evitable.

Felicitamos al grupo de Ovalle y colaboradores quienes nos presentan en este número su experiencia3. Ellos contribuyen al conocimiento sobre esta materia, sobre el uso y factibilidad de implementación de metodologías como el CORM en nuestro medio público/privado y demuestran que el trabajo exhaustivo, serio y comprometido puede ser replicado en otros centros del país para así aliviar en algo el dolor presente y reducir la incertidumbre futura que experimentan la madre y su familia en la muerte inesperada del hijo anhelado.

\section{REFERENCIAS}

1. GBD 2015 Child Mortality Collaborators. Global, regional, national, and selected subnational levels of stillbirths, neonatal, infant, and under-5 mortality, 1980-2015: a systematic analysis for the Global Burden of Disease Study 2015. Lancet. 2016; 388(10053):1725-1774.

2. Ovalle A, Fuentes A, Chacón V, Espinoza C, González R, Kakarieka $E$ et al. Método de clasificacion de mortinatos según condición obstetrica relevante de la muerte fetal, en un hospital público de Chile (Método CORM) Rev Med Chile 2016; 144: 1020-1028

3. Ovalle A, Valderrama O, Alvarado J, Kakarieka E. El método de clasificación de mortinatos "condición obstétrica relevante de la muerte fetal" (CORM) reduce la frecuencia de muerte fetal de causa inexplicable.

Dr. Eghon Guzmán B.

Past-Presidente

SOCHOG 